\title{
Normal Immunoglobulin G (IgG) for Therapeutic Use (Intravenous Ig) Contain Antiidiotypic Specificities against an Immunodominant, Disease-associated, Cross-reactive Idiotype of Human Anti-Thyroglobulin Autoantibodies
}

\author{
Gilles Dietrich and Michel D. Kazatchkine \\ Unité d'Immunopathologie and Institut National de la Santé et de la Recherche Médicale U28, Hôpital Broussais, 75014 Paris, France
}

\begin{abstract}
Pooled normal polyspecific IgG for therapeutic use (IVIg) contain anti-idiotypes against idiotypic determinants expressed by autoantibodies from patients with a variety of autoimmune diseases. In the present study, antiidiotypes in IVIg are shown to recognize a cross-reactive idiotype on human anti-thyroglobulin (TG) autoantibodies, that was defined by heterologous antiidiotypic antibodies, termed anti-T44 antibodies. The T44 idiotype is located outside the antibody-combining site of anti-TG autoantibodies. $F\left(a^{\prime}\right)_{2}$ fragments from anti-T44 antibodies inhibited the binding of IVIg to affinitypurified $\mathbf{F}\left(\mathbf{a b}^{\prime}\right)_{2}$ anti-TG autoantibodies. Anti-T44 antibodies bound to $F\left(a^{\prime}\right)_{2}$ fragments of patients' antibodies, which were retained on an affinity column of Sepharose-bound $F\left(a^{\prime}\right)_{2}$ fragments from IVIg, but not to $F\left(a b^{\prime}\right)_{2}$ fragments from the effluent of the column. The T44 idiotype was expressed on antibodies that bound to IVIg from eight of nine patients with autoimmune thyroiditis, but not on IVIg-binding Igs from healthy individuals. A small amount of the T44 idiotype was also expressed on the fraction of IVIg that bound to itself upon affinity chromatography. The T44 idiotype was cross-reactive between antibodies from patients with autoimmune thyroiditis. Thus, IVIg contain antiidiotypic antibodies directed against an immunodominant disease-associated cross-reactive $\alpha$-idiotype of human anti-TG autoantibodies. These results support the concept that IVIg may be beneficial in selected autoimmune diseases by modulating the function of the idiotypic network. (J. Clin. Invest. 1990. 85:620-625.) idiotypes • idiotypic network • autoimmune thyroiditis • autoimmunity • intravenous immunoglobulins
\end{abstract}

\section{Introduction}

Intravenous infusion of pooled normal polyspecific IgG for therapeutic use (IVIg) ${ }^{1}$ has resulted in clinical improvement and/or decrease in autoantibody titer in a number of human

Address reprint requests to Dr. M. D. Kazatchkine, Unité d'Immunopathologie, Hôpital Broussais, 96 rue Didot, 75674 Paris, Cedex 14 France.

Received for publication 26 July 1989 and in revised form 12 October 1989.

1. Abbreviations used in this paper: IVIg, intravenous Igs for therapeutic use; TG, thyroglobulin.

J. Clin. Invest.

(c) The American Society for Clinical Investigation, Inc.

0021-9738/90/03/0620/06 \$2.00

Volume 85, March 1990, 620-625 autoimmune diseases (1-8). Several lines of evidence suggest that IVIg contain antiidiotypes against a variety of autoantibodies from patients with autoimmune diseases and against natural autoantibodies from normal individuals (9): (a) F( $\left.\mathrm{ab}^{\prime}\right)_{2}$ fragments from IVIg inhibit the binding of autoantibodies to their autoantigens $(8,9 \mathrm{a}, 10$, and 11$) ;(b) \mathrm{F}\left(\mathrm{ab}^{\prime}\right)_{2}$ fragments with autoantibody activity are specifically retained on affinity columns of Sepharose-bound $F\left(a^{\prime}\right)_{2}$ fragments from IVIg (10-12); (c) IVIg contain no antibody specificities against the most common allotypes expressed in the $F\left(a b^{\prime}\right)_{2}$ region of human IgG (11). In the present study, IVIg are shown to share antiidiotypic specificities against human anti-thyroglobulin (TG) autoantibodies with heterologous antiidiotypes. The idiotype recognized by IVIg and heterologous antiidiotypic antibodies is an immunodominant cross-reactive $\alpha$ idiotype expressed on anti-TG autoantibodies from patients with autoimmune thyroiditis. These results further support the concept that IVIg may be beneficial in selected autoimmune diseases by modulating the function of the idiotypic network.

\section{Methods}

Patients and Igs. Sera were obtained from nine patients (Dem., Ben., Mou., Tan., Dum., Bar., Cai., Bat., and Vau.) with circulating anti-TG autoantibodies and a clinical diagnosis of Hashimoto's disease, and from five healthy individuals (Har., Rous., Rou., Ma., and Cav.). The IgG fraction was prepared from serum by chromatography on DEAE Trisacryl (IBF, Villeneuve la Garenne, France). IVIg were Sandoglobulin $^{\oplus}$ (Sandoz Ltd., Basel, Switzerland), a preparation of intact human polyspecific IgG for therapeutic use obtained from a large pool of plasma from normal donors. $F\left(a b^{\prime}\right)_{2}$ fragments were prepared from patients' IgG and from IVIg by pepsin digestion and chromatography on protein A Sepharose (Pharmacia Fine Chemicals, Uppsala, Sweden). $\mathrm{F}\left(\mathrm{ab}^{\prime}\right)_{2}$ preparations were free of detectable $\mathrm{Fc}$ fragments as assessed by ELISA. Protein concentrations were determined spectrophotometrically using an absorption coefficient of 1.4 for $\operatorname{IgG}$ and $F\left(a b^{\prime}\right)_{2}$ at $280 \mathrm{~nm}$.

Affinity chromatography. $\mathrm{F}\left(\mathrm{ab}^{\prime}\right)_{2}$ fragments containing anti-TG activity were chromatographed on Sepharose-bound $F\left(a b^{\prime}\right)_{2}$ fragments from IVIg as previously described (12). $F\left(a b^{\prime}\right)_{2}$ fragments that were eluted from the columns with $0.1 \mathrm{M}$ glycine $\mathrm{pH} 2.8$ are referred to as "acid eluates" in this paper. The fall-through of the affinity columns is designated as "effluent." Acid eluates were pooled and concentrated by ultrafiltration on an Amicon PM 10 membrane (Amicon, Danvers, MA).

Preparation of rabbit antiidiotypic antibodies directed against human anti-TG antibodies. $\mathrm{F}\left(\mathrm{ab}^{\prime}\right)_{2}$ fragments from patient Dem.'s IgG that had been affinity-purified on Sepharose-bound human TG (a kind gift from Dr. Olivier, INSERM U 283, Paris) were used as immunogen. Purified TG contained no contaminating IgG, as assessed by SDS PAGE analysis and ELISA. A New Zealand white rabbit was immunized by injecting $150 \mu \mathrm{g}$ of immunizing $F\left(a b^{\prime}\right)_{2}$ fragments emulsified in complete Freund's adjuvant intradermally at multiple sites. The 
rabbit was boosted with $110 \mu \mathrm{g}$ of $\mathrm{F}\left(\mathrm{ab}^{\prime}\right)_{2}$ in incomplete Freund's adjuvant every week for 3 wk. Anti-T44 antiserum was the serum obtained 1 wk after the last booster injection. IgG and $\mathrm{F}\left(\mathrm{ab}^{\prime}\right)_{2}$ fragments were prepared from anti-T44 antiserum as described above. Anti-T44 IgG and $F\left(a b^{\prime}\right)_{2}$ fragments were sequentially adsorbed on Sepharose-bound human myeloma $x$ and $\lambda$ light chains (a kind gift from Dr. F. Danon, Hôpital St Louis, Paris), Sepharose-bound human TG and Sepharose-bound $F\left(a b^{\prime}\right)_{2}$ fragments from IVIg by batch adsorptions overnight at $4^{\circ} \mathrm{C}$. $\mathrm{F}\left(\mathrm{ab}^{\prime}\right)_{2}$ fragments were also prepared from IgG from normal rabbits.

ELISA. The antiidiotypic activity of anti-T44 antibodies was characterized using an ELISA. 96-well ELISA plates (Central European Biotechnology Laboratories, Angers, France) were coated with the immunizing, affinity-purified anti-TG $\mathrm{F}\left(\mathrm{ab}^{\prime}\right)_{2}$ fragments from patient Dem. $(2 \mu \mathrm{g} / \mathrm{ml})$, or appropriate control human $\mathrm{F}\left(\mathrm{ab}^{\prime}\right)_{2}$ fragments overnight at $4^{\circ} \mathrm{C}$. Uncoated sites were blocked with $1 \%$ gelatin (Gibco Laboratories, Grand Island, NY) in PBS for $1 \mathrm{~h}$ at $20^{\circ} \mathrm{C}$ and the plates were washed with PBS. Increasing amounts of anti-T44 IgG in PBSgelatin were added to wells for $2 \mathrm{~h}$ at $20^{\circ} \mathrm{C}$. After four washes with PBS, bound $\mathrm{IgG}$ was revealed using peroxidase-labeled goat anti-rabbit $\mathrm{Fc}$ antibodies (Cappel Laboratories, Cochranville, PA) that had been extensively adsorbed with purified human $F\left(a b^{\prime}\right)_{2}$ fragments.

Competitive binding experiments were performed by incubating increasing concentrations of anti-T44 $\mathrm{F}\left(\mathrm{ab} \mathrm{b}^{\prime}\right)_{2}$ fragments or normal rabbit $\mathrm{F}\left(\mathrm{ab}^{\prime}\right)_{2}$ fragments with $1 \mathrm{mg} / \mathrm{ml}$ of IVIg in PBS-gelatin for $2 \mathrm{~h}$ at $20^{\circ} \mathrm{C}$ in microtiter wells coated with affinity-purified anti-TG $\mathrm{F}\left(\mathrm{ab}^{\prime}\right)_{2}$ fragments from patient Dem. After washing the plates with PBS containing $0.1 \%$ Tween 20 (Sigma Chemical Co., St Louis, MO), bound IVIg was revealed using peroxidase-labeled goat anti-human Fc gamma antibodies (Biosys, Compiègne, France). Inhibition of the binding of IVIg was calculated as follows:

$$
\left[1-\left(\frac{\text { IVIg bound in the presence of competitor }}{\text { IVIg bound in the absence of competitor }}\right)\right] \times 100 \text {. }
$$

\section{Results}

Specificity of anti-T44 antiidiotypic antibodies. The antiidiotypic specificity of anti-T44 IgG was determined by assessing the relative ability of the antibody to bind to immunizing anti-TG $\mathrm{F}\left(\mathrm{ab}^{\prime}\right)_{2}$ autoantibodies and to control $\mathrm{F}\left(\mathrm{ab}^{\prime}\right)_{2}$ antibodies. Anti-T44 IgG was first adsorbed with human myeloma $\kappa$ and $\lambda$ chains. As shown in Fig. 1, adsorbed anti-T44 IgG strongly bound to the immunizing $F\left(a^{\prime}\right)_{2}$ fragments from patient Dem. that had been affinity-purified on Sepharose-bound human TG, whereas it weakly bound to patient Dem.'s $\mathrm{F}\left(\mathrm{ab}^{\prime}\right)_{2}$ fragments from the effluent of the TG affinity column and to $F\left(a b^{\prime}\right)_{2}$ fragments from a normal individual with no detectable anti-TG antibodies. Fig. 2 shows that anti-T44 IgG that had been adsorbed with human TG and IVIg bound to patient Dem.'s affinity-purified $F\left(a^{\prime}\right)_{2}$ anti-TG antibodies but exhibited no binding capacity for $\mathrm{F}\left(\mathrm{ab}^{\prime}\right)_{2}$ fragments from IVIg. Affinity-purified anti-TG $\mathrm{F}\left(\mathrm{ab}^{\prime}\right)_{2}$ did not contain anti-rabbit $\mathrm{Fc}$ gamma activity as assessed by the lack of ability of normal rabbit IgG that had been preadsorbed with human $F\left(a b^{\prime}\right)_{2}$ to bind to insolubilized anti-TG $\mathrm{F}\left(\mathrm{ab}^{\prime}\right)_{2}$ from patient Dem. (data not shown). Anti-T44 IgG adsorbed with TG and IVIg did not bind to patient Dem.'s $F\left(a^{\prime}\right)_{2}$ fragments from the effluent of the TG affinity column. Thus, adsorbed anti-T44 IgG specifically recognizes $F\left(a b^{\prime}\right)_{2}$ fragments from patient Dem., which exhibit anti-TG activity.

Adsorbed anti-T44 $\mathrm{F}\left(\mathrm{ab}^{\prime}\right)_{2}$ fragments did not inhibit the binding of patient Dem.'s IgG to insolubilized human TG, indicating that anti-T44 antibodies are preferentially directed

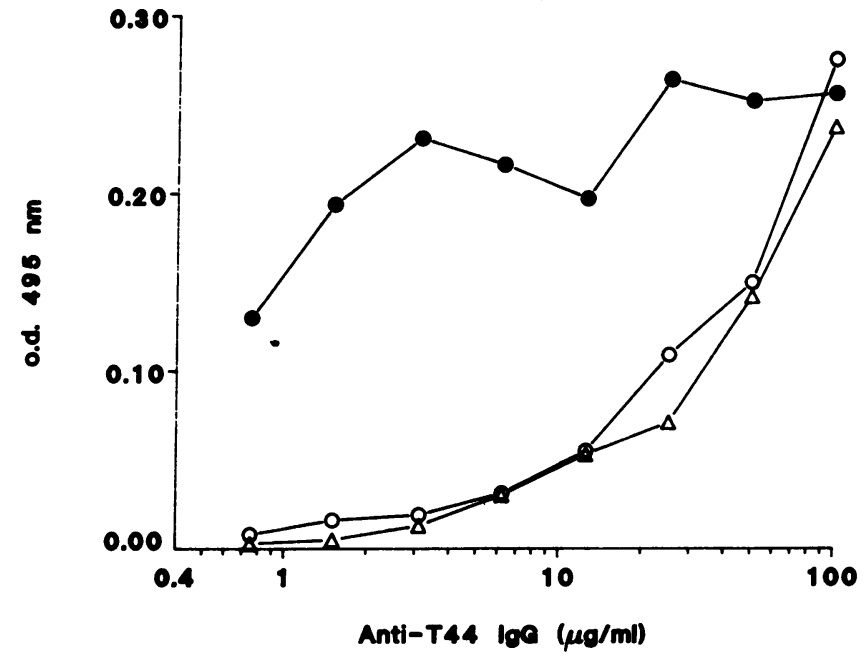

Figure 1. Antiidiotypic specificity of rabbit anti-T44 IgG. Anti-T44 IgG was adsorbed with human $\kappa$ and $\lambda$ chains and assessed for its ability to bind to affinity-purified patient Dem.'s $\mathrm{F}\left(\mathrm{ab}^{\prime}\right)_{2}$ anti-TG antibodies (๑), patient Dem.'s $F\left(a^{\prime}\right)_{2}$ fragments with no anti-TG specificity (o), and $F\left(a b^{\prime}\right)_{2}$ fragments from a normal individual with no detectable anti-TG antibodies $(\Delta)$, using an ELISA.

against idiotypic determinants located outside the antibodycombining site of patient Dem.'s anti-TG autoantibodies (data not shown).

Shared antiidiotypic specificities between anti-T44 IgG and IVIg. IVIg contains antibody species that recognize human anti-TG autoantibodies (10). Preliminary experiments demonstrated that IVIg bound to affinity-purified anti-TG $\mathrm{F}\left(\mathrm{ab}^{\prime}\right)_{2}$ fragments from patient Dem. in a dose-dependent manner (data not shown). The experiments depicted in Figs. 3 and 4 indicate that rabbit anti-T44 IgG share antiidiotypic specificities with IVIg. Fig. 3 shows that anti-T44 antiidiotypic $\mathrm{F}\left(\mathrm{ab}^{\prime}\right)_{2}$ antibodies exhibited an $\sim 10$-fold higher capacity to inhibit the binding of IVIg to affinity-purified anti-TG $\mathrm{F}\left(\mathrm{ab}^{\prime}\right)_{2}$ antibodies from patient Dem. than normal rabbit $F\left(a b^{\prime}\right)_{2}$. In

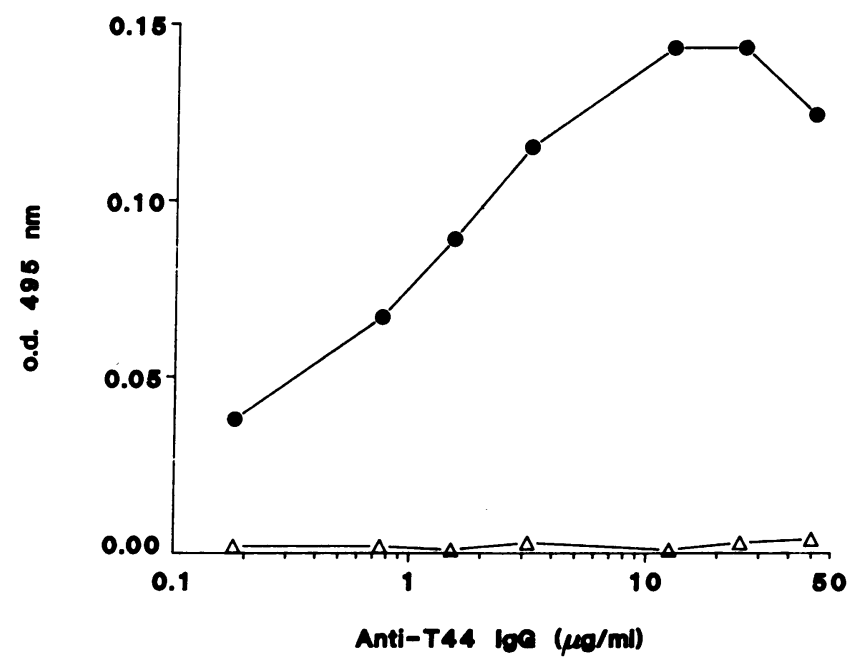

Figure 2. Antiidiotypic specificity of rabbit anti-T44 IgG. Binding of anti-T44 IgG that had been adsorbed with human TG and IVIg to affinity-purified $\mathrm{F}\left(\mathrm{ab}^{\prime}\right)_{2}$ anti-TG antibodies from patient Dem. (•) and $F\left(a b^{\prime}\right)_{2}$ from $\operatorname{IVIg}(\Delta)$. 


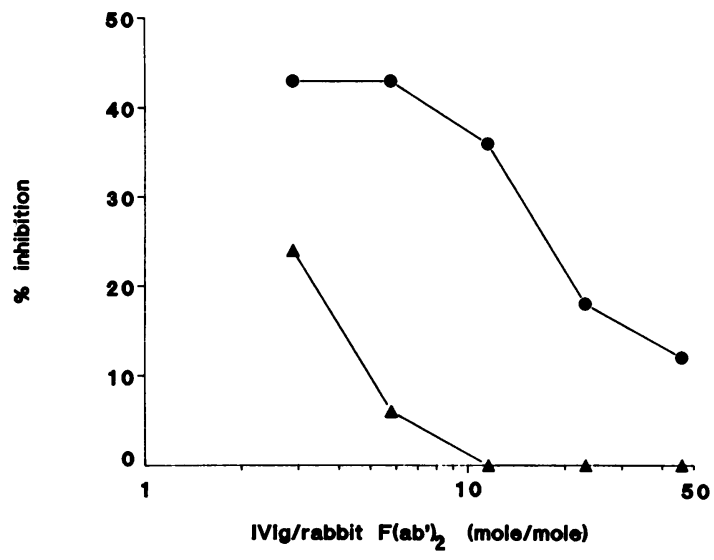

Figure 3. Inhibition of the binding of IVIg to insolubilized affinitypurified anti-TG $\mathrm{F}\left(\mathrm{ab}^{\prime}\right)_{2}$ autoantibodies from patient Dem. by rabbit anti-T44 $\mathrm{F}\left(\mathrm{ab}^{\prime}\right)_{2}$ fragments $(\bullet)$ and $\mathrm{F}\left(\mathrm{ab}^{\prime}\right)_{2}$ fragments from normal rabbit $\operatorname{IgG}(\mathbf{\Lambda})$.

the experiment depicted in Fig. 4, $F\left(a^{\prime}\right)_{2}$ fragments from patient Dem. were first chromatographed on Sepharose-bound $\mathrm{F}\left(\mathrm{ab}^{\prime}\right)_{2}$ fragments from IVIg. The presence of the T44 idiotype was then assessed in the acid-eluate and in the effluent from the column, and in unchromatographed $F\left(a^{\prime}\right)_{2}$. The figure shows that anti-T44 IgG that had been adsorbed with TG and IVIg exclusively bound to $F\left(a b^{\prime}\right)_{2}$ that had been acid-eluted from the IVIg column. Binding of anti-T44 IgG to the fragments occurred through the antibody-combining site of antiT44 IgG since no binding was observed with normal rabbit IgG that had been preadsorbed with IVIg. The observation that anti-T44 bound to eluted $F\left(a^{\prime}\right)_{2}$ fragments from the column and did not bind to $F\left(a b^{\prime}\right)_{2}$ fragments in the affluent and to unchromatographed $\mathrm{F}\left(\mathrm{ab}^{\prime}\right)_{2}$ fragments confirms that antiT44 specificities are not of antiallotypic nature. Thus, IVIg and anti-T44 IgG share antiidiotypic specificities directed against idiotypes expressed by patient Dem.'s anti-TG autoantibodies.

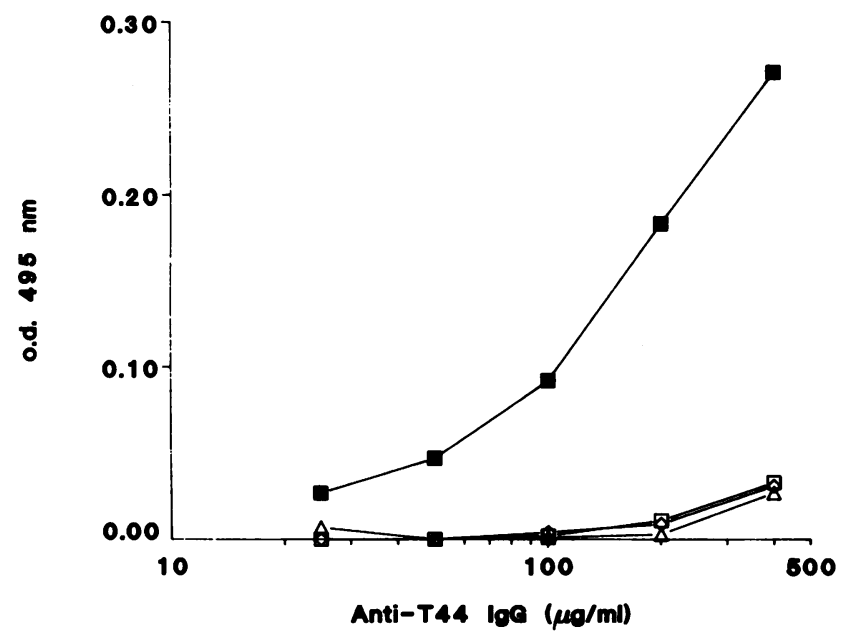

Figure 4. Binding of anti-T44 $\mathrm{IgG}$ to $\mathrm{F}\left(\mathrm{ab}^{\prime}\right)_{2}$ fragments from patient Dem.'s IgG that had been acid-eluted from Sepharose-bound $F\left(a^{\prime}\right)_{2}$ from IVIg $(\omega), F\left(a b^{\prime}\right)_{2}$ fragments from the effluent of the IVIg affinity column ( $\square$ ), unchromatographed $F\left(a^{\prime}\right)_{2}$ fragments from patient Dem.'s IgG $(\diamond)$, and $F\left(a b^{\prime}\right)_{2}$ from IVIg $(\Delta)$. ELISA plates were coated with $40 \mu \mathrm{g} / \mathrm{ml}$ of $\mathrm{F}\left(\mathrm{ab}^{\prime}\right)_{2}$ fragments.
Anti-T44 IgG and IVIg recognize a cross-reactive idiotype expressed by anti-TG autoantibodies from patients with $\mathrm{Ha}$ shimoto's disease. $\mathrm{F}\left(\mathrm{ab}^{\prime}\right)_{2}$ fragments from IgG of nine patients with Hashimoto's disease were chromatographed on Sepharose-bound $F\left(a b^{\prime}\right)_{2}$ fragments from IVIg. The presence of the T44 idiotype was assessed in the acid-eluted fragments and in the effluent of the columns. As shown in Fig. 5, acid-eluted $F\left(a b^{\prime}\right)_{2}$ fragments from eight of nine patients were recognized by antiidiotypic anti-T44 IgG, whereas $F\left(a b^{\prime}\right)_{2}$ fragments in the effluents from the columns did not express the T44 idiotype. Acid-eluted $\mathrm{F}\left(\mathrm{ab}^{\prime}\right)_{2}$ fragments from patients' IgG did not contain detectable antibodies against rabbit $\mathrm{Fc}$ fragments. Thus, IVIg contain antiidiotypic antibodies directed against a cross-reactive idiotype expressed by eight of nine anti-TG autoantibodies from patients with Hashimoto's disease, which is also recognized by anti-T44 IgG. In contrast, $F\left(a^{\prime}\right)_{2}$ fragments of IgG from normal individuals that bind to IVIg-Sepharose did not express the T44 idiotype (Fig. 6). As shown in the figure, IVIg (i.e., a large pool of IgG from normals) contained antibody species expressing the idiotype recognized by both IVIg and anti-T44 IgG.

Cross-reactivity between patients' autoantibodies expressing the T44 idiotype was further investigated in the following experiment: $F\left(a b^{\prime}\right)_{2}$ fragments from patient Cai.'s IgG were chromatographed on Sepharose-bound $F\left(a b^{\prime}\right)_{2}$ fragments from IVIg. Acid-eluted $F\left(a b^{\prime}\right)_{2}$ fragments expressed relatively high amounts of the T44 idiotype (Fig. 5). The fragments were insolubilized on ELISA plates. The relative ability of $\mathrm{F}\left(\mathrm{ab}^{\prime}\right)_{2}$ fragments from IgG of three other patients and from IVIg that had been acid-eluted from IVIg-Sepharose to inhibit the bind-

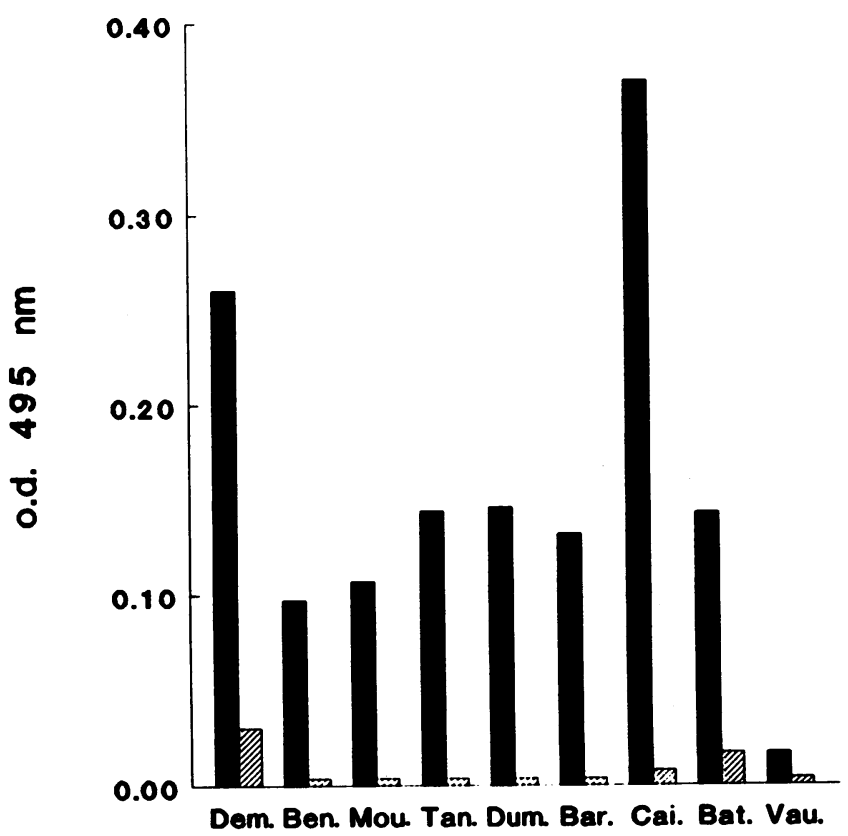

Figure 5. Anti-T44 IgG and IVIg recognize a cross-reactive idiotype on anti-TG autoantibodies. $\mathrm{F}\left(\mathrm{ab}^{\prime}\right)_{2}$ fragments from IgG of nine patients with anti-TG antibodies were chromatographed on Sepharosebound $F\left(a b^{\prime}\right)_{2}$ fragments from IVIg. The acid eluted $F\left(a b^{\prime}\right)_{2}$ fragments $(\square)$ and $F\left(a b^{\prime}\right)_{2}$ fragments in the effluent $(\square)$ were assessed for their ability to bind anti-T44 IgG. The figure shows the maximal binding of anti-T44 IgG to $F\left(a b^{\prime}\right)_{2}$ fragments that was achieved. Normal rabbit IgG did not bind to insolubilized $F\left(a b^{\prime}\right)_{2}$ fragments. 


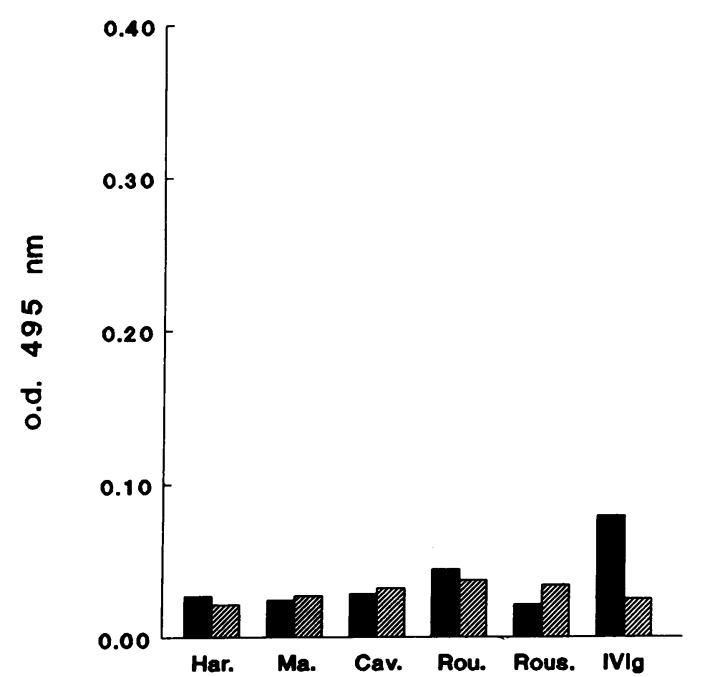

Figure 6. Lack of expression of the T44 idiotype by $F\left(a b^{\prime}\right)_{2}$ fragments from IgG of normal individuals. The experiment and symbols are the same as those depicted in Fig. 5. The last line on the right of the figure depicts the result obtained with IVIg.

ing of anti-T44 IgG to insolubilized patient Cai.'s $\mathrm{F}\left(\mathrm{ab}^{\prime}\right)_{2}$ fragments was then assessed. As shown in Fig. 7, $F\left(a^{\prime}\right)_{2}$ fragments from IVIg and $F\left(a b^{\prime}\right)_{2}$ fragments from the three patients' IgG inhibited the binding of anti-T44 IgG to patient Cai.'s F $\left(\mathrm{ab}^{\prime}\right)_{2}$ fragments in a dose-dependent fashion. Thus, autoantibodies from patients with Hashimoto's disease and some antibody

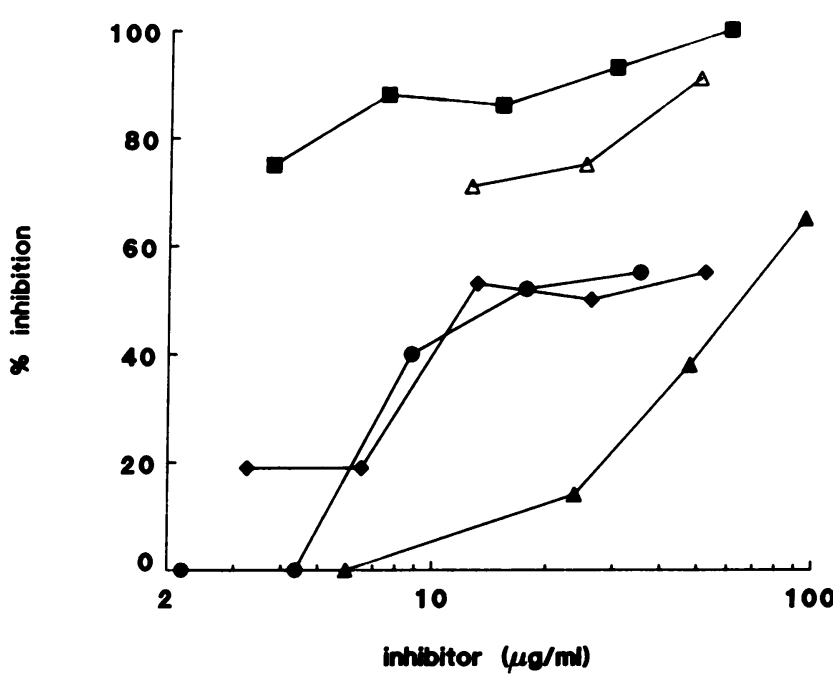

Figure 7. Cross-reactivity between T44 idiotype-bearing anti-TG autoantibodies. $\mathrm{F}\left(\mathrm{ab}^{\prime}\right)_{2}$ fragments from patient Cai.'s IgG that had been acid-eluted from Sepharose-bound IVIg (see Fig. 5) were insolubilized on ELISA plates. The relative ability of $F\left(a b^{\prime}\right)_{2}$ fragments from

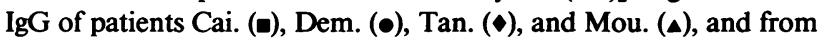
IVIg $(\Delta)$ that had been acid-eluted from Sepharose-bound IVIg were assessed for their ability to inhibit the binding of anti-T44 IgG to patient Cai.'s $\mathrm{F}\left(\mathrm{ab}^{\prime}\right)_{2}$ fragments. The binding of anti-T44 IgG to patient Cai.'s $F\left(a b^{\prime}\right)_{2}$ fragments in the absence of inhibitor $F\left(a b^{\prime}\right)_{2}$ fragments or in the presence of irrelevant $F\left(a b^{\prime}\right)_{2}$, gave an optical density of $0.105 \pm 0.008$ species in IVIg express a cross-reactive idiotype recognized by anti-T44 antibodies and antiidiotypes in IVIg.

\section{Discussion}

IVIg contain antiidiotypes against idiotypic determinants expressed by autoantibodies from patients with a variety of autoimmune diseases, including anti-Factor VIII, anti-DNA, anti-TG, antiintrinsic factor, and antiperipheral nerve (9a) autoantibodies $(8,10$, and 11$)$. The present study demonstrates that antiidiotypes in IVIg directed against anti-TG autoantibodies recognize an immunodominant $\alpha$ idiotype shared by autoantibodies from patients with autoimmune thyroiditis and not found on antibodies from individually tested healthy subjects.

We prepared rabbit antiidiotypic antibodies (anti-T44 antibodies) that exclusively bound to affinity-purified anti-TG autoantibodies from a patient (Dem.) with autoimmune thyroiditis. Anti-T44 antibodies did not inhibit the binding of the patient's autoantibodies to human TG, indicating that the immunodominant idiotype recognized by the antiserum is an $\alpha$ idiotype, located outside the antibody-combining site of the patient's anti-TG autoantibodies. Anti-T44 antibodies that had been adsorbed with IVIg and TG did not bind to the fraction of patient's antibodies that was devoid of anti-TG activity, nor to $\mathrm{F}\left(\mathrm{ab}^{\prime}\right)_{2}$ fragments from normal individuals and $\mathrm{F}\left(\mathrm{ab}^{\prime}\right)_{2}$ fragments from IVIg.

Two lines of evidence indicated that idiotypic determinants within the T44 idiotype are recognized by antiidiotypes in IVIg: (a) $\mathrm{F}\left(\mathrm{ab}^{\prime}\right)_{2}$ fragments from anti-T44 antibodies inhibited the binding of IVIg to affinity-purified $\mathrm{F}\left(\mathrm{ab}^{\prime}\right)_{2}$ autoantibodies with anti-TG activity, indicating that anti-T44 antibodies and antiidiotypes in IVIg compete for the binding to idiotypic determinants expressed by the patient's anti-TG autoantibodies; (b) Anti-T44 antibodies bound to $F\left(a b^{\prime}\right)_{2}$ fragments of the patient's antibodies that were retained on an affinity column of Sepharose-bound $F\left(a b^{\prime}\right)_{2}$ fragments from IVIg. Inasmuch as anti-T44 antibodies did not bind to unchromatographed antibodies from the patient, the expression of the T44 idiotype appeared to be associated with the patient's antibody species that were recognized by anti-idiotypes in IVIg and that were enriched in the acid-eluted fraction from the IVIg affinity column. Thus, IVIg and anti-T44 antibodies recognize the same idiotypes on anti-TG autoantibodies from patient Dem.

The idiotype recognized by anti-T44 antibodies and by IVIg was found to be expressed by antibodies from eight of nine patients with autoimmune thyroiditis, but not by antibodies from healthy individuals. Thus, the T44 idiotype was detected in the fraction of patients' $F\left(a b^{\prime}\right)_{2}$ fragments that was retained on affinity columns of IVIg, but was not detected in patients' $F\left(a b^{\prime}\right)_{2}$ fragments from the effluent of the columns, nor in $F\left(a b^{\prime}\right)_{2}$ fragments from normal individuals that bound to IVIg. Anti-TG autoantibodies from patients with autoimmune thyroiditis differed in their relative ability to inhibit the binding of anti-T44 IgG to anti-TG $F\left(a^{\prime}\right)_{2}$ antibodies from one of the patients that had been affinity-purified on IVIg. The lack of retention of detectable T44-positive IgG upon affinity chromatography of normal IgG on IVIg indicates that if normal IgG contains some T44-expressing antibodies, these would be present in very low amounts. 
It is possible that autoantibodies from different patients differ in the relative amount of expressed cross-reactive idiotype. Alternatively, differences in the ability of the patients' autoantibodies to inhibit the binding of anti-T44 to a specific anti-TG autoantibody could reflect the presence in patients' IgG of other antibody species that are involved in idiotypicantiidiotypic interactions with IVIg. In any case, the experiment indicated that anti-TG autoantibodies from different patients express similar and/or overlapping idiotypes that are part of the cross-reactive T44 idiotype.

IgG from normal individuals and IVIg contain anti-TG activity $(10,13)$. The finding of a specific expression of the T44 idiotype on patients' autoantibodies, but not on antibodies from normal subjects, suggest that $\mathrm{T} 44$ could be an antigenic marker of disease-associated autoantibodies. Cross-reactive idiotypes have previously been found on anti-TG autoantibodies from patients with autoimmune thyroiditis $(14,15)$ that were not expressed by antibodies lacking anti-TG specificity (14). Some of the cross-reactive idiotypes of anti-TG antibodies were associated with the antibody-combining site of the autoantibodies (14). Expression of a cross-reactive idiotype has been found on autoantibodies to rat TG of $67 \%$ of individual animals from the Buffalo strain of rats with spontaneous autoimmune thyroiditis (16). Idiotypic cross-reactivity has also been observed between mouse monoclonal antibodies recognizing highly conserved epitopes of human TG (17). In addition, spontaneous autoantibodies to TG from rats share an interspecies cross-reactive idiotype (18) and human autoantibodies from patients with Hashimoto's disease recognize interspecies cross-reactive epitopes (19). The finding in IVIg of antiidiotypes against a disease-associated idiotype on anti-TG autoantibodies, suggests that the antiidiotypic repertoire of IVIg includes antibodies against potential targets for therapeutic immunomanipulation. The results also suggest that T44expressing anti-TG autoantibodies are clones that expand in patients with autoimmune thyroiditis and that may be downregulated by specific antiidiotypes in healthy individuals.

IVIg are pools of IgG from large numbers of healthy donors. The presence in IVIg of detectable antiidiotypic activity against autoantibodies is probably the consequence of additive contributions of antiidiotypic specificities from normal individuals (8). In this context, the probability of finding antiidiotypic activity against cross-reactive idiotypes is higher than that of antiidiotypes against private idiotypic determinants. An interesting observation was that of a small amount of T44 idiotype expressed in IVIg, which may reflect the coexistence of idiotype and antiidiotype in the pool. The idiotype could be expressed on $A b_{1}$ or $A b_{3}$ antibodies of IgG from a fraction of donors.

Several mechanisms have been postulated to explain the beneficial effect that has been seen with IVIg in selected autoimmune diseases, including inhibition of the clearance of autoantibody-coated target cells through Fc receptor blockade (20), induction of specific suppressor T cells (21), and antiidiotypic suppression of autoantibodies $(5,8,9 \mathrm{a}$, and 22$)$. The finding in IVIg of antiidiotypes against cross-reactive, diseaseassociated idiotypes of autoantibodies support the hypothesis that IVIg could be effective by antiidiotypic suppression and by partially restoring defective connectivity within the idiotypic network of patients with autoimmune diseases.

\section{Acknowledgments}

The authors thank Françoise Rossi for fruitful discussions and Martine Pehuet for providing sera. The secretarial assistance of $\mathrm{N}$. Levee is gratefully acknowledged.

This work was supported by Institut National de la Santé et de la Recherche Médicale, France, Sandoz Ltd., Basel, Switzerland, and Institut Mérieux, Lyon, France.

\section{References}

1. Imbach, P., V. d'Apuzzo, C. Baumgartner, A. Hist, A. Morell, E. Rossi, M. Schöni, M. Vest, and H. P. Wagner. 1981. High dose intravenous gammaglobulin for idiopathic thrombocytopenic purpura in childhood. Lancet. i: $1228-1230$.

2. Pollack, S., C. Cunningham-Rundles, E. M. Smithwick, S. Barandun, and R. A. Good. 1982. High-dose intravenous gammaglobulin for autoimmune neutropenia. N. Engl. J. Med. 309:243-255.

3. Mc Intyre, E. A., D. C. Linch, M. G. Maccy, and A. C. Newland. 1985. Successful response to intravenous immunoglobulin in autoimmune haemolytic anaemia. Br. J. Haematol. 60:287-288.

4. Clauvel, J. P., W. Vainchenker, A. Herrera, K. Dellagi, G. Vinci, A. Tabillo, and C. Lacombe. 1983. Treatment of pure red cell aplasia by high dose intravenous immunoglobulins. Br. J. Haematol. 55:380382.

5. Mc Guire, W. A., H. H. Yong, E. Bruno, J. Brandt, R. Bridell, T. D. Coates, and R. Hoffman. 1987. Treatment of antibody-mediated pure red cell aplasia with high dose intravenous gammaglobulin. $N$. Engl. J. Med. 317:1004-1008.

6. Gadjos, P. H., H. Outin, D. Elkharrat, D. Brunel, P. de RohantChabot, J. C. Raphaël, M. Goulon-Goeau, and E. Morel. 1984. Highdose intravenous immunoglobulin for myasthenia gravis. Lancet. i:406-407.

7. Vermeulen, M., F. G. A. Van Der Meche, J. D. Speelman, A. Weber, and H. F. M. Busch. 1985. Plasma and gammaglobulin infusion in chronic inflammatory polyneuropathy. J. Neurol. Sci. 70:317326.

8. Sultan, Y., M. D. Kazatchkine, P. Maisonneuve, and U. E. Nydegger. 1984. Anti-idiotypic suppression to autoantibodies of Factor VIII by high-dose intravenous gammaglobulin. Lancet. ii:765-768.

9. Rossi, F., G. Dietrich, and M. D. Kazatchkine. 1989. Anti-idiotypes against autoantibodies in normal immunoglobulins: evidence for network regulation of human autoimmune responses. Immunol. Rev. 110:135-149.

9a. Van Doorn, P. A., A. Brand, F. Rossi, M. Vermeulen, and M. D. Kazatchkine. 1989. On the mechanism of high dose intravenous immunoglobulin treatment of patients with chronic inflammatory demyelinating polyneuropathy. J. Neuroimmunol. In press.

10. Rossi, F., and M. D. Kazatchkine. 1989. Anti-idiotypes against autoantibodies in pooled normal human polyspecific immunoglobulins. J. Immunol. 143:4104-4109.

11. Rossi, F., Y. Sultan, and M. D. Kazatchkine. 1988. Anti-idiotypes against autoantibodies and alloantibodies to VIII:C (anti-hemophilic factor) are present in therapeutic polyspecific normal immunoglobulins. Clin. Exp. Immunol. 74:311-316.

12. Sultan, Y., F. Rossi, and M. D. Kazatchkine. 1987. Recovery from anti-VIII:C (anti-hemophilic factor) autoimmune disease is dependent on generation of anti-idiotypes against anti-VIII:C autoantibodies. Proc. Natl. Acad. Sci. USA. 84:828-831.

13. Guilbert, B., G. Dighiero, and S. Avrameas. 1982. Naturally occurring antibodies against nine common antigens in human sera. I. Detection, isolation, and characterization. J. Immunol. 128:27792787. 
14. Delves, P. J., and I. M. Roitt. 1984. Idiotypic determinants on human thyroglobulin autoantibodies derived from the serum of Hashimoto patients and EB virus transformed cell lines. Clin. Exp. Immunol. 57:33-40.

15. Matsuyama, T., J. Fukumori, and H. Tanaka. 1983. Evidence of unique idiotypic determinants and similar idiotypic determinants on human anti-thyroglobulin antibodies. Clin. Exp. Immunol. 51:381-386.

16. Zanetti, M., and P. E. Bigazzi. 1981. Anti-idiotypic immunity and autoimmunity. I. In vitro and in vivo effects of anti-idiotypic antibodies to spontaneously occurring autoantibodies to rat thyroglobulin. Eur. J. Immunol. 11:187-195.

17. Zanetti, M., M. De Baets, and J. Rogers. 1983. High degree of idiotypic cross-reactivity among murine monoclonal antibodies to thyroglobulin. J. Immunol. 131:2452-2457.

18. Zanetti, M., R. W. Barton, and P. E. Bigazzi. 1983. Anti-idiotypic immunity and autoimmunity. II. Idiotypic determinants of auto- antibodies and lymphocytes in spontaneous and experimentally induced autoimmune thyroiditis. Cell. Immunol. 75:292-299.

19. Kohno, Y., H. Nakajima, and O. Tarutani. 1985. Interspecies cross-reactive determinants of thyroglobulin recognized by autoantibodies. Clin. Exp. Immunol. 61:44-48.

20. Fehr, J., V. Hofmann, and V. Kappeler. 1982. Transient reversal of thrombocytopenia in idiopathic thrombocytopenic purpura by high-dose intravenous gammaglobulin. N. Engl. J. Med. 306:12541258.

21. Delfraissy, J. F., G. Tchernia, Y. Laurian, C. Wallon, P. Galanaud, and J. Dormont. 1985. Suppressor cell function after intravenous gammaglobulin treatment in adult idiopathic thrombocytopenic purpura. Br. J. Haematol. 60:315-322.

22. Berchtold, P., G. Dale, P. Tani, and R. McMillan. 1988. Inhibition of autoantibody binding to platelet glycoprotein IIb/IIIa by antiidiotypic antibodies in intravenous gammaglobulin. Blood. 72(Suppl. 1):261a. (Abstr.) 